\title{
De trabalhador a pedinte
}

\author{
Giuseppina Rosaria de Grazia \\ Universidade de Santo Amaro (UNISA)
}

\section{De trabalhador a pedinte}

Resumo: Este artigo tem por objetivo discutir as políticas sociais vigentes nos últimos anos, incluindo os reflexos na subjetividade do trabalhador, a partir dos efeitos gerados tanto pela vivência do desemprego prolongado, como pela conseqüente dependência de programas sociais e ajudas de terceiros para garantir a própria subsistência. Relatos de pesquisa qualitativa, realizada no município de São Paulo, mostram o constrangimento provocado por essa dependência e inconformidade com a negação do direito ao trabalho. Além de insuficientes no combate às verdadeiras causas da desigualdade, as políticas compensatórias, fundadas na ortodoxia liberal, reforçam a fragmentação e a submissão das forças do trabalho, reduzem a população envolvida a meros objetos de intervenção, e dificultam ainda mais a construção de um projeto e identidade de classe, onde os trabalhadores possam interferir organizada e coletivamente, assumindo o papel de sujeitos na formulação da política e dos rumos da sociedade.

Palavras-chave: trabalho, precarização do trabalho, políticas sociais, dependência.

\section{From Worker to Petitioner}

Abstract: The purpose of this article is to discuss current social policies and their subjective repercussions on workers' lives, particularly the effects of prolonged unemployment and the consequent dependence on social programs and assistance from third parties to guarantee subsistence. Results of a qualitative study conducted in the municipality of São Paulo show the unease caused by this dependence and the disgust with the denial of the right to work. In addition to insufficiently combating the true causes of inequality, compensatory policies based on liberal orthodoxy reinforce the fragmentation and submission of the efforts of labor, reduce the population involved to mere objects of intervention and impede the construction of a class project and identity, through which workers could have organized and collective influence, assuming the role of agents in the formulation of policies and in the direction of society. Key words: work, precariousness of work, social policies, dependence. 


\section{Introdução}

Eu como mãe, me sinto humilhada. Pra dizer a verdade, me sinto um lixo.

Do trabalho formal ao trabalho assalariado sem registro em carteira... daí para serviços temporários... 'bicos' esporádicos, (em atividades lícitas ou ilícitas)... e, finalmente, a necessidade de recorrer aos programas sociais governamentais, buscar ajuda em igrejas, Ongs, ou ainda, depender da solidariedade de vizinhos e da caridade alheia.

Não necessariamente nessa ordem, essa tem sido a dramática trajetória facilmente revelada por qualquer levantamento junto aos camelôs que atravancam as ruas das grandes cidades - muitos deles o tempo todo fugindo da polícia como se fossem bandidos; ou junto às centenas de 'catadores', aos moradores de rua, àqueles nas filas dos serviços assistenciais, ou, ainda, junto aos sentenciados nas cadeias. Em grande parte desses casos, não é difícil encontrar um denominador comum: a impossibilidade de garantir a sobrevivência de forma regular e autônoma, através do único recurso disponível aos trabalhadores: a venda de sua força de trabalho.

Depoimentos colhidos numa pesquisa qualitativa, realizada em 2005 no município de São Paulo ${ }^{1}$, permitem colocar uma lente de aumento na realidade objetiva vivida por grandes parcelas da população vendo-se paulatinamente transformadas da condição de trabalhadores à de 'pedintes' - assim como na percepção que elas demonstram ter a respeito da própria situação: o constrangimento decorrente da necessidade de depender da ajuda de terceiros, a ausência de qualquer sentimento de pertencimento de classe e a conseqüente sensação de impotência e falta de perspectiva para qualquer reação, principalmente coletiva.

A partir desse enfoque, pretende-se discutir as atuais políticas sociais não apenas tendo em vista seus resultados econômicos, mas também os reflexos produzidos na consciência individual e coletiva, seja pela realidade atual do mundo do trabalho, seja pelas respostas oferecidas pelo Estado, em particular a partir dos anos 1990.

\section{0 avanço da precarização do trabalho e do de- semprego estrutural}

Os vários depoimentos coletados na pesquisa citada mostram trajetórias mais ou menos comuns de diversas pessoas que perderam o emprego formal há alguns anos e não mais conseguiram recuperar nem o trabalho registrado, nem o salário. Passaram a viver de 'bicos', em trabalhos totalmente precarizados, sem qualquer proteção legal, sem regularidade e quase sempre sub-remunerados. No início dos depoimentos aqui transcritos, considerou-se importante registrar a idade e o bairro de origem dos depoentes.

C., 24 anos, Parque do Gato (o marido trabalhou como ajudante geral, com carteira assinada até 1997): "Depois ficou desempregado. Nunca mais arrumou serviço registrado. Agora tem uma banca onde conserta relógio na (Av.) Prestes Maia. Não tem ganho fixo: um dia faz 10 [reais], outro faz 15, outro não faz nada."

M. L., 29 anos, Favela Heliópolis (trabalhou com carteira assinada até 98):

"Depois não trabalhei mais registrada, porque não achei. É difícil arrumar serviço registrado. Então a gente pega o que aparece."

G., 43 anos, Favela do Tubo, Grajaú (sobre o marido): "É pedreiro. Sempre só faz bico: trabalha dois, três dias, às vezes dez, quinze dias, e fica dois, três meses parado. Logo que vim morar com ele, ele trabalhava direto. De uns três, quatro anos pra cá tá difícil demais o emprego: fica mais tempo parado que trabalhando.”

Os depoimentos acima são confirmados, embora palidamente, por todas as estatísticas oficiais a respeito do desemprego e do contínuo aumento da 'informalidade' (eufemismo para nomear o desemprego disfarçado sob a forma de trabalhos precários). As regiões metropolitanas foram as mais afetadas pela queda do emprego formal. As nove regiões pesquisadas pelo $\mathrm{IBGE}^{2}$ que, em 1980, concentravam praticamente a metade das pessoas que trabalhavam com carteira assinada em todo o país, 20 anos depois passam a concentrar apenas $37,4 \%$, conforme registrado em André Campos, Marcio Pochmann, Ricardo Amorin e Ronnie Silva, (CAMPOS et al., 2003, p. 93-94). A 'lei da selva' em que se transformou a disputa para se conseguir um ganha-pão estende-se até ao campo do trabalho mais precarizado.

S., 34 anos, Favela do Iguaçu, Jardim Planalto: “Até pra catar papelão na rua tá concorrido. Antes, ia duas, três vezes por semana, conseguia ganhar 50 [reais] por dia. Hoje não se consegue nem um real. Você vai com o carrinho vazio e volta com ele mais vazio ainda. Quando você chega já tem um monte de gente em cima. É igual urubu na carniça. Dá briga direto por causa de uma garrafa, de um papelão... Até pra fazer isso tá difícil."

G., 38 anos, Cidade Tiradentes (vende cafezinho e salgados, feitos por ela, nas feiras):

(Ultimamente) "tem tanta gente vendendo café... 
que não dá pra nada. Antes vendia 70, 80 salgados. Hoje vendo só uns 30, 40. Agora as coisas pioraram de vez."

J., Favela da Vila Industrial (desempregada há mais de 2 anos; o marido cata papelão na rua):

"Ele trabalha com carrinho emprestado. Vende no ferro-velho. Não tá dando porque é muita gente que tá catando no meio do mundo; o papelão baixou... Antes dava. Tem vez que a gente passa muito apertado.(No ano passado) ele ficou doente: teve tuberculose de tanto ele trabalhar na chuva, no frio... Porque a gente sofre, sofre mesmo."

Com o advento do chamado desemprego estrutural, o antigo e sempre imprescindível exército de reserva não mais admite a mesma rotatividade, nem flutua apenas ao sabor de fatores conjunturais. Com o fechamento crescente e definitivo de postos de trabalho, uma grande parcela da população tende a permanecer indefinidamente fora do mercado. Essas pessoas nem mais constam das estatísticas de desemprego ${ }^{3}$.

\section{Q., 31 anos, Favela Pantanal:}

"Tô num sufoco triste... Só Deus mesmo. Peço todo dia pra arranjar um trabalho. Espalhei tanto currículo por aí... de faxina, de limpeza, entrego nessas firma de reciclagem. Entreguei em tudo que é lugar... Fiz inscrição pra frente de trabalho... não consegui nada até agora."

\section{C., 24 anos, Parque do Gato:}

"Eu e outra colega já batemos Santana, Bom Retiro, tudo. Por isso que o pobre muitas vezes se desespera. Porque ele quer trabalhar e não pode."

\section{M., 39 anos, Favela Heliópolis:}

"Fiz curso de telemarketing, telefonia... mas querem registro em carteira. Dizem que não adianta o curso sem registro na carteira. Como é que a gente vai ter experiência se não deixam."
Em primeiro lugar, se pudéssemos rastrear o histórico de vida de cada um desses milhares de 'excluídos' ${ }^{5}$, iríamos encontrar dados abundantes e demonstrativos da enorme massa de 'trabalho não-pago' ao longo da vida, assim como na história de seus país, avós, bisavós... Ao contrário da sempre presente vinculação entre pobreza e 'acomodação' disseminada pelo pensamento liberal dominante - e profundamente enraizada mesmo entre alguns assistentes sociais bem intencionados - uma investigação que buscasse ultrapassar as aparências imediatas, iria identificar nesses extratos da população histórias de intenso e opressivo trabalho, de cujos frutos sempre foram (aí sim) excluídos. Por isso, apesar da ofensiva do pensamento pós-moderno, os paradigmas supostamente ultrapassados continuam essenciais para se chegar até à verdadeira 'raiz' da desigualdade e da questão social (IAMAMOTO, 1998) que permanece fundamentalmente a mesma, apesar das novas 'formas' mais 'flexíveis' de extração do trabalho excedente e apropriação privada das riquezas produzidas pelo conjunto da força de trabalho.

\section{G., 43 anos, Favela do Tubo, Grajaú: \\ "Se trabalhar 'enricasse', eu já era podre de rica, porque desde a idade de 8 anos eu trabalhava la- vando roupa pros outros. Com 11 anos, fui traba- lhar numa casa..." \\ G., 18 anos, Favela do Moinho: \\ "Não tive infância. Comecei trabalhar com 8 anos. Eu vendia bala, engraxava sapato, vendia refrige- rante e cerveja no trem."}

No caso do Brasil, além da mais valia, apropriada secularmente pelos representantes do capital, o pagamento da força de trabalho abaixo de seu valor, isto é, insuficiente até para a custear a própria subsistência, permite, segundo os cálculos de Pochmann (2006a), que 78\% da riqueza nacional esteja em mãos de $10 \%$ da população.

Em segundo lugar, a enorme pressão das grandes parcelas fora do mercado de trabalho vem contribuindo para rebaixamentos ainda maiores de salários, mesmo entre aqueles que permanecem vinculados a um emprego estável. Apesar do pequeno aumento de empregos e da renda do trabalhador nos dois últimos anos, a massa salarial como um todo ainda é $15 \%$ inferior à de 1996, segundo os dados da Pesquisa Nacional por Amostra de Domicílios (PNAD, 2005).

\section{a enorme pressão das gran-}

des parcelas fora do mercado

de trabalho vem contribuindo

para rebaixamentos ainda

maiores de salários, mesmo

entre aqueles que permane-

cem vinculados a um emprego

estável. ra de baixo crescimento econômico como a atual ${ }^{4}$. a acumulação do capital e tornando possível o 'milagre' dos enormes aumentos da taxa de lucro, mesmo numa conjuntu- 
Se a queda do poder aquisitivo foi significativa mesmo para quem conseguiu manter ou recuperar o emprego, é fácil imaginar o que ocorreu com quem acabou fazendo dos 'bicos' seu único meio de sobrevivência ${ }^{6}$.

As conhecidas dificuldades decorrentes da ausência de um salário regular, somadas ao medo de engrossar as fileiras do desemprego por parte de quem ainda está empregado, exercem intensa pressão, para que as pessoas se sujeitem a situações totalmente irregulares, aviltantes, em postos sub-remunerados e sem respeito à legislação. Tudo isso praticamente sem resistência por parte das organizações sindicais ou de qualquer movimento coletivo. Não por acaso, uma das conseqüências do desemprego mais vantajosas ao capital é justamente a fragilização ou aniquilamento da mobilização e organização coletiva dos trabalhadores.

L., 32 anos, Barão de Piracicaba (marido trabalha como ajudante de pedreiro para uma construtora. Tem carteira assinada, mas...):

“...é sempre contrato temporário de 60, 90 dias, às vezes de oito meses. Entre um contrato e outro fica parado. Essa última vez ficou três meses parado".

\section{S., 30 anos, Recanto do Paraíso, Perus:}

"Quando arrumo quatro faxinas por mês, ganho 100 reais (25 por dia). Dou graças a Deus quando alguém diz: só posso pagar 10. Porque tá difícil de arrumar".

\section{R., 24 anos, Favela Águas Espraiadas, Jabaquara (sobre o novo emprego do marido): \\ "Tá achando uma maravilha... porque ficou 1 ano e 6 meses desempregado. Pra ele tá tudo ótimo".}

Esse agravamento da situação das camadas populares, além de deitar suas raízes na estrutura social que há 500 anos vem sendo mantida a favor das classes dominantes, é o resultado direto da política econômica adotada particularmente a partir dos anos 1990. Neste período o receituário neoliberal torna-se hegemônico, e a reestruturação produtiva se aprofunda com a finalidade de enfrentar a guerra de competitividade numa economia cada vez mais globalizada e recuperar a taxa de lucro do capital.

Se nos países desenvolvidos as tentativas de superação da crise do capital também ocorreram às custas do corte de empregos e benefícios sociais, num país que não chegou nem perto do Estado de Bem-Estar, as conseqüências para os trabalhadores foram devastadoras.

Uma leitura dialética da realidade, porém, permite perceber que o problema (e também a solução), é que, se por um lado, o sistema se alimenta, tal como abutre, da miséria crescente e degradação do tecido social, por outro lado, o alastramento de uma realidade cada vez mais caótica amplia e multiplica uma seqüência de crises que parece não ter fim. Com efeito, nunca foi tão visível a contradição - cuja tendência à agudização fora prevista por Marx desde o século 19 - entre o enorme avanço da capacidade de produção e geração de riquezas, ao mesmo tempo em que aumentam as dificuldades da força de trabalho para usufruir dessa abundância. Dificuldades geradas pelas próprias relações estabelecidas no modo de produção capitalista, cuja limitação dos empregos e salários, travando o consumo e, conseqüentemente, os investimentos na produção, acaba desencadeando crises e voltando-se contra a própria 'ordem' do capital.

\section{Estratégias de sobrevivência}

Como conseqüência direta das dificuldades crescentes na venda da força de trabalho, a subsistência de uma parcela cada vez mais ampla de trabalhadores passa a depender das políticas governamentais de transferência de renda, da ajuda de organizações filantrópicas, vizinhos, parentes, ou de esmolas propriamente ditas.Nem mesmo as necessidades mais primárias conseguem ser supridas de forma autônoma.

Na pesquisa em questão, constatou-se que a grande maioria dos entrevistados $(70 \%)$ não consegue sequer garantir a alimentação da família com os próprios recursos, dependendo total ou parcialmente da ajuda de terceiros (recebem cestas básicas fornecidas pelo poder público, igrejas ou entidades filantrópicas; comida de vizinhos ou parentes; catam nos lixos e nos restos de feiras; pedem nos mercados, ou nas casas, etc). Entre os 30\% restantes, outras necessidades básicas acabam não atendidas, conforme expressões várias vezes repetidas: "ou se come, ou se paga aluguel"; "ou se come, ou se compra roupas". Mais de 50\% 
das famílias entrevistadas também se referiu ao fato de vestir apenas roupas doadas, já usadas.

A pesquisa permite perceber ainda algumas diferenças entre os moradores da periferia e os das regiões mais centrais. Nestas últimas, a facilidade de acesso aos alimentos é maior - seja remexendo nas lixeiras, recolhendo e revendendo latinhas, papelão, etc, seja pela proximidade de supermercados, restaurantes, etc, ou ainda pela maior quantidade de entidades filantrópicas que distribuem alimentos. Os moradores das regiões mais periféricas, além de também recorrerem a igrejas e entidades de ajuda, dependem em grande parte da solidariedade dos próprios vizinhos ou parentes, que, em geral, também passam por dificuldades.

V., Favela Recanto da Paz, Perus (sozinha, quatro filhos, sem qualquer renda):

"Ganhei uma cestinha... tô comendo... Teve dia que eles (crianças) passaram o dia sem comer. Uma irmã (que mora próximo) me ajuda, mas ela também não pode: tem cinco filhos, marido desempregado."

\section{S., 34 anos, Favela Jd. Planalto:}

"Quando é uma hora da tarde, todo o povo da favela vai pra ver se pega alguma coisa na feira. Quando a gente chega, o povo já tem feito a rapa. A gente não vai se meter a brigar por causa de um repolho...(O que ganha) não dá pra nada. É roupa, é calçado... eles [filhos] usam tudo que é dado pelos outros... Comida também, os vizinhos dão, as madrinhas ajudam. Elas chegam e perguntam: você quer um pé de alface? Você quer isso ou aquilo? Vou dizer que não?"

\section{M., 40 anos, ocupação Prestes Maia:}

“Aqui em São Paulo só passa fome se quiser. $\mathrm{Na} 25$ de Março, dão comida todo dia: sopa, marmitex... Roupa e cesta básica: quando a gente precisa, a gente pede, e eles marcam pra ir buscar. São pessoas da Igreja. Só passa necessidade se quiser."

Uma outra questão evidenciada na pesquisa, certamente com sérias seqüelas na estrutura psíquica e mental, refere-se à própria forma de acesso aos bens indispensáveis à subsistência. Os diversos depoimentos mostram sentimentos de constrangimento, vergonha e humilhação, resultantes da necessidade de pedir, de depender quase que permanentemente da ajuda de outros para garantir o primeiro direito básico do ser humano: comer.

\section{L., 32 anos, Barão de Piracicaba:}

"Não tô tendo condição de comprar leite. Mistura... essa, quando tem, aí é que é novidade mesmo. (O que se ganha) não dá de jeito nenhum. Leite, que eu acho que toda criança devia tomar no café da manhã, uma carne, um danone, que as crianças vê os outros comer e ficam com vontade.Roupa, calçado... os meninos usam mais roupa de doação. Eu como mãe me sinto humilhada. Quando não tem comida dentro de casa, a gente pega marmitex: é uma perua que dá pros mendigos. Na Praça Princesa Isabel, dão pão e banana. Toda terça-feira a gente vai: pra dizer a verdade me sinto um lixo. Não queria ter muito. Queria ter só o básico. Acho que toda pessoa sonha com isso."

S., 27 anos, Cidade Tiradentes (desempregada, para alimentar os filhos, pede esmolas nas casas):

"Uns batem a porta na cara, outros cantam, fingem que não tão escutando Um dia venho com pouco, outro dia venho sem nada. Dá vergonha, porque batem a porta na cara... Queria um emprego, né, que aí já vai no mercado, compra o que precisa."

\section{L., 49 anos, Favela do Moinho:}

"Quando não tem carne, vou no mercado, peço umas gordurinhas pra fazer sabão, aí aproveito... porque eles dão uns pedaços bons. Não passo fome porque minha filha me ajuda com comida, mantimentos, roupa. Roupa nem se fala, porque a gente não compra. A gente ganha sempre. Preferia comprar: é tão bom a gente poder comprar... Gosto de comprar o tecido e fazer um vestido bem composto."

\section{J., 41 anos, Marsilac:}

"Leite, pego no Viva Leite e na creche. Verdura, etc, pego no mercado... nos sacos que o mercado separa para o lixo. Ás vezes eles acham ruim. A gente pega e divide pro pessoal que fica do lado de fora esperando: 15 a 20 pessoas. Às vezes dá briga: quando é carne, ninguém quer dividir. $\mathrm{O}$ mercado (em Santo Amaro) deixa só duas pessoas entrar: uma da Pastoral e outra, deficiente: elas chamam as pessoas que ficam do lado de fora esperando e dividem. Vou uma vez por semana lá. Eu me sinto mal, porque aquilo ali é uma humilhação... a gente se submete por causa dos filhos. A gente vai mesmo porque precisa, que se eu tivesse um trabalho..."

Percebe-se que a relativa facilidade de acesso, pelo menos aos bens de primeira necessidade nas grandes cidades, onde as pessoas vivem em proximidade com nichos de grande fartura, tem como contrapartida um reforço da dependência, do estímulo à postura de pedinte, à busca desesperada e desordenada do 'salvese quem puder' (e como puder).

Longe de expressar a famosa 'acomodação', uma análise mais acurada e menos preconceituosa revelaria uma realidade muito mais complexa do que aquela alardeada por freqüentes e superficiais interpretações. A começar pelo fato de que não está sendo permitido a boa parte dessas pessoas escolher entre pedir ou trabalhar.Quando, além de todos os direitos fundamen- 
tais, o próprio direito ao trabalho é negado, no mundo subjugado pelo império da mercadoria, a opção acaba se reduzindo a 'pedir ou roubar' - expressão diversas vezes verbalizada pelos entrevistados e constatada no cotidiano das cidades por diversas outras falas e ações. Além disso, a convivência diária com os inúmeros exemplos de vida miserável como única 'recompensa' a longos anos de trabalho, também não oferece nenhum incentivo, particularmente aos jovens, para seguir o mesmo caminho.

\section{L., 29 anos, Favela Heliópolis (grávida, desem- pregada): \\ "Dá um desespero quando você olha pro lado e não vê nada. Ou você pára de comer, diminui na comida e compra as coisas pro bebê, ou sai pedin- do na rua roupa usada. Já fiz isso... não vou mentir [chora]. Sinto vergonha, as pessoas mandam a gente trabalhar. Mas trabalhar como? Eu falo: se a senho- ra me der alguma coisa pra fazer, eu faço."}

\section{A institucionalização da esmola}

Das famílias entrevistadas, $30 \%$ participam de algum tipo de programa de transferência de renda. Apesar do valor irrisório, o benefício é considerado um complemento importante da renda familiar. A questão mais significativa a ser pensada, porém, é o fato de que, pelo menos no que se refere a essas famílias, ao final do período de concessão do benefício elas estarão na mesma situação em que estavam quando começaram a recebê-lo, o que indica a probabilidade de que continuarão dependentes e necessitando de novos auxílios.

D., 19 anos, ocupação Prestes Maia (sozinha, com três crianças, recebe 150 reais do Renda Mínima): "Ajuda muito porque compro remédio, fralda, leite, sapato. Só com os 200 (de salário) não ia conseguir."

\section{L., 32 anos, Barão de Piracicaba:}

(O Bolsa Família) é uma ajuda: gasto com comida. "Porque as outras coisas a gente passa, mas comida não. Se cortasse, ia fazer muita falta."

C., 24 anos, Parque do Gato (126 reais do Renda Mínima complementam a renda familiar de $\mathrm{R} \$ 300$ ): "Uso pra comprar leite, fraldas pro G. Ajuda bastante. Seria mais importante as pessoas ter serviço, ter o primeiro emprego. E quem dá emprego pra uma mulher que tem quatro filhos? O governo devia facilitar isso."

As polêmicas em torno da eficácia dos programas de transferência de renda são extensas e não é objetivo, e nem o espaço permite, tratar de todos os aspectos envolvidos. Na grande imprensa, principal porta-voz da concepção neoliberal, a grande preocupação é saber se as famílias beneficiadas estão dentro das camadas definidas como as mais pobres do país. Apesar de algumas discordâncias, há um amplo consenso, o que inclui elogios do FMI, Banco Mundial, em torno do Bolsa Família como um programa de eficiente focalização. O que significa dizer que é um programa que gasta pouco porque "corretamente restrito aos mais' miseráveis dentro do universo dos extratos já situados na extrema pobreza. Mesmo assim não são raras as reclamações contra o aumento desse tipo de gastos.

Bem mais freqüentes são as críticas em relação ao suposto grande aumento de gastos públicos nos últimos dois anos com o salário mínimo e os demais benefícios a ele vinculados, pagos pela Previdência (aposentadorias rurais e o Benefício de Prestação Continuada), os quais, somados aos cerca de R\$ 6 bilhões gastos com o Bolsa Família, consumiram só no último ano em torno de $\mathrm{R} \$ 80$ bilhões. Páginas e páginas de jornais diariamente vêm alertando a respeito do 'potencial explosivo' desses gastos, que representariam uma ameaça à estabilidade e ao crescimento do país.

Para estancar o 'excesso' de gastos governamentais, vários estudos têm sido produzidos, em especial pelo Instituto de Pesquisa Econômica Aplicada (IPEA), vinculado ao Ministério do Planejamento, com a finalidade de demonstrar que "o programa de transferência de renda é duas vezes e meia mais eficiente do que o aumento do salário mínimo no combate à pobreza e quase sete vezes mais efetivo no combate à extrema pobreza". O argumento principal é o de que no Bolsa Família se economizam $60 \%$ dos recursos gastos no aumento do mínimo para a mesma redução da pobreza, e $75 \%$ no combate à extrema pobreza (MÍNIMO..., 2006). Isto é, a preocupação primordial é sempre a economia de recursos.

Embora minoritários, outros estudos têm demonstrado o contrário. Sergei Soares, economista do IPEA, demonstra que mais de $3 / 4$ da redução da desigualdade, apontada pela PNAD, principalmente entre 2003 e 2005, deve-se ao aumento do salário mínimo e a uma redistribuição de renda entre os rendimentos auferidos no mercado de trabalho. Apenas $1 / 4$ poderia ser debitada aos programas de transferência de renda, em especial o Bolsa Família. Além dos trabalhadores diretamente beneficiados pelo aumento do salário mínimo, os benefícios previdenciários recebidos por idosos e deficientes, contribuíram mais que o Bolsa Família para a redução da pobreza (CONSTANTINO, 2006).

A preocupação com o excesso de gastos públicos, porém, desaparece por completo quando o assunto se refere ao pagamento dos juros da dívida 
pública e outros tantos gastos sabidamente supérfluos. Conforme os dados elaborados por Marcio Pochmann, os juros pagos (só em 2005 foram 157 bilhões de reais, isto é, quase o dobro dos referidos 80 bilhões) consomem quase toda a renda arrecadada através dos impostos ${ }^{7}$, além de terem como destinatários apenas os bancos e os $20 \%$ mais abastados do país (que investem nas transações financeiras com títulos da dívida do governo). "O montante de juros equivale a 22 vezes o Bolsa-Família [...] e a quase quatro vezes o déficit da Previdência" (POCHMANN, 2006b). Ou seja, fazer economia nos gastos sociais, assim como em novos investimentos, é a única maneira de poder garantir o superavit para o pagamento dos juros aos credores nacionais e internacionais. Estes gastos, porém, são considerados inquestionáveis e fora de qualquer discussão pelos ideólogos do pensamento liberal.

A obsessão pela diminuição dos 'gastos excessivos' do Estado (quando dirigidos às classes trabalhadoras) que seriam os responsáveis pela diminuição da rentabilidade do capital e por toda crise da sociedade capitalista desde os anos 1970 - está entre as principais causas do desmoronamento do Estado do Bem-Estar Social e o fim das políticas sociais de caráter universal.

A maioria dos programas de transferência de renda, atualmente em vigor, tem sua origem justamente na necessidade de substituir aquelas políticas alicerçadas sobre a clara noção de 'direitos universais' conquistados durante o ascenso dos movimentos operários no período fordista. Desenvolvida originalmente por Friedman, um dos principais teóricos do neoliberalismo, a idéia da renda mínima para 'os menos afortunados', gerida pelo poder público - um dos poucos papéis reservados ao Estado na política neoliberal (NETTO, 2001, p.80) - ajusta-se perfeitamente ao novo modelo produtivo e político: deixa intacto o sistema de exploração, não pressiona pela redistribuição dos lucros e diminui os perigos de convulsões sociais, mantendo a enorme parcela dos 'beneficiados' de cabeça baixa e grata aos seus 'benfeitores'.

Assim, para ter acesso a qualquer um dos serviços públicos, programas ou benefícios que efetivem direitos sociais básicos e universais (garantidos inclusive pelas leis do País), a crescente massa de excluídos do mercado de trabalho ou trabalhadores que recebem salários irrisórios têm que estar dispostos a se humilhar como pedintes por meses ou anos em longas filas de espera, disputando com milhares de outros em situações tão ou mais desesperadoras. É o que ocorre entre os milhares de cadastrados nos projetos habitacionais, nos projetos de transferência de renda; entre os que disputam cestas básicas, entre os que aguardam vagas nos hospitais, entre as centenas de mães disputando vaga nas creches, e assim por diante.

Ironicamente, uma boa parte dos recursos retirados dos serviços públicos, hoje é dispendida no conjunto de processos burocráticos necessários para efetivar a seleção dos 'finalistas contemplados': na elaboração de minuciosos critérios cada vez mais seletivos, na fiscalização do cumprimento desses critérios, etc. É o único setor em que se admite um aumento nos gastos e no número de funcionários.

Apesar de necessários, como apoio emergencial às situações de carência que demandam urgência deação, os programas de complementação de renda - hoje unificados no Bolsa Família - vêm sua eficácia limitada pela inexistência de políticas macroeconômicas de incentivo ao crescimento econômico e às demais políticas necessárias à criação de empregos. Dessa forma impedem a emancipação das famílias atendidas, tornando-as permanentemente dependentes de novas e contínuas ajudas. Medidas emergenciais só surtiriam um efeito emancipatório se, ao término do período do benefício, estivessem criadas as condições de superação dos fatores que originaram as dificuldades.

De outro lado, a intervenção estatal cada vez mais precária e focalizada, necessariamente implica na privatização dos serviços públicos e na volta da 'filantropização' como formas de tratar a questão social (MONTAÑO, 2002). Práticas voluntárias, forçosamente pontuais, localizadas, fragmentadas e precárias, por mais bem intencionadas que sejam, passam a substituir a ação pública.

Devido à tradição histórica brasileira de um poder público ineficaz, burocrático e corrupto, o discurso de 'satanização' do Estado cai como uma luva no imaginário da opinião pública. Por outro lado, no mesmo discurso neoliberal, com função ideológica precisa, a 'sociedade civil' - em seu sentido de oposição ao Estado - é idealizada (vejam-se os constantes elogios da mídia às iniciativas do Terceiro Setor, aos projetos de Responsabilidade Social das empresas, etc), contribuindo para ocultar que é justamente no seu interior que se encontra a principal contradição da 
sociedade de classes - os interesses opostos entre capital e trabalho, principais raízes da desigualdade.

\section{A dependência}

Enquanto os maiores debates permanecem circunscritos à esfera da eficácia econômica, a análise dos efeitos do aumento da dependência na 'subjetividade' das pessoas, cuja subsistência está cada vez mais presa a esse tipo de políticas e outras formas de assistencialismo, parece ocupar um lugar secundário, restringindo-se a uma pequena parte da produção acadêmica, ou dos movimentos sociais e a grupos políticos mais críticos. As marcas, decorrentes desse reforço da dependência, subjugação e assistencialismo, podem ser observadas não só nas reações individuais, nos sinais de degradação do ser humano, mas também no efeito de tornar ainda mais distante qualquer possibilidade de viabilização de um projeto coletivo de classe.

$\mathrm{O}$ aumento da dependência em relação aos programas sociais é confirmado por estudo do CEBRAP (CEBRAP, 2006) a partir dos dados da PNAD: em $1995,89 \%$ da renda dos $10 \%$ mais pobres da população era proveniente do trabalho; em 2004, apenas $48 \%$. O que indica que mais da metade dos recursos que entram nas famílias dessa faixa da população deve-se a outras fontes, principalmente aos programas de transferência de renda, segundo Álvaro Comin, autor do estudo. "Se esses dados forem consistentes", diz Lena Lavinas, economista da Universidade Federal do Rio de Janeiro (UFRJ), "eles mostram que não estamos complementando a renda para os mais pobres viverem melhor, mas gerando uma renda para viverem quase que exclusivamente dela. Estão deixando de ser trabalhadores para se tornarem assistidos. Isso é dramático" (LAVINAS apud GÓIS, 2006).

Apesar da freqüente preocupação de alguns assistentes sociais com as 'mentiras' fabricadas por diversos usuários para serem incluídos na restrita demanda ou para não perderem os benefícios ${ }^{8}$, os depoimentos colhidos mostram a distância entre as políticas desenvolvidas e os anseios da população envolvida.

Quando estimuladas a falar sobre seus sonhos, desejos, o que gostariam de mudar em suas vidas, é praticamente unânime a aspiração das pessoas entrevistadas por apenas dois direitos básicos: trabalho e moradia ${ }^{9}$. Os anseios mais explicitados foram os de viver num lugar com o mínimo de dignidade "[...] que (meus filhos) tivessem uma cama e um quarto pra eles dormir" (S., 29 anos, Favela Paraisópolis) -, ter direito ao trabalho, direito de poder sustentar a família, dar um futuro aos filhos sem precisar depender da boa vontade de terceiros, sem precisar humilhar-se. Nenhum dos entrevistados manifestou-se no sentido de querer continuar recebendo benefícios ou de querer que alguém se responsabilize pelo sustento da família. Expressando um certo incômodo por precisar depender sempre de ajuda, a preferência por um emprego e uma renda própria aparece constantemente.

\section{M.L., 49 anos, Favela do Moinho:}

"Em primeiro lugar, gostaria de ter um empreguinho. Sair cedo, ter horário pra voltar... queria ser independente, não dever nada pra ninguém. Coisa melhor do mundo é ter um dinheirinho no fim do mês e saber o que fazer."

\section{J., 41 anos, Marsilac: \\ "O que eu queria mesmo, de verdade, era um servi- ço fixo pra mim e pra meu marido. Não é porque sou pobre e não quero ajuda, mas é porque a gente tem vergonha (de viver pedindo ou catando no lixo)."}

Além de passarem ao longe das verdadeiras causas e da solução da pobreza e desigualdade, num país onde historicamente os problemas sociais foram relegados a práticas clientelistas, com a prestação de favores em troca da submissão, dependência e tutela das classes trabalhadoras, o reforço do Estado assistencialista, das práticas filantrópicas, da esmola agora institucionalizada, fortalece a dominação de classe, dificultando as tentativas de reação organizada e independente dos trabalhadores como sujeitos históricos e políticos. Tentativas que, a duras penas, vinham sendo implementadas entre o fim dos anos 1970 e a década de 1980, e que naufragaram na conjuntura econômica e política que veio a seguir.

As políticas públicas, implementadas a partir do reconhecimento de direitos universais (que não dependem de 'seleção', com base em critérios estabelecidos em cada governo, em cada programa), apesar de apresentadas pela história oficial sempre como resultado da benevolência unilateral de algum governante (Princesa Isabel e a abolição; Getúlio Vargas e a CLT, etc), em geral expressaram momentos históricos em que as classes subalternas conseguiram organizar-se e impor uma correlação de forças favorável aos seus interesses. Além disso, direitos estabelecidos e consolidados podem ser 'cobrados' (com mais eficácia ainda quando coletivamente), ao contrário da esperada submissão individual, necessária para inclusão em programas pontuais.

Em duas recentes entrevistas, Francisco de Oliveira (apud CARIELLO, 2006) diz que o Bolsa Família, mais que um programa simplesmente assistencialista, é um

[...] instrumento de controle em primeiro lugar. Restaura uma espécie de clientelismo que não leva à política [...]. É pelas suas carências que você é clas- 
sificado perante o Estado [...]. Acabou a história de você depender das relações de força, das relações de classe para desenhar as políticas sociais [...]. Quanto você tem de renda, qual é seu estatuto de miserável, aí a política é desenhada. É uma clara regressão.

Nesse sentido, acrescenta o autor, o governo Lula "exclui o proletariado, que 'não é mais sujeito, mas objeto da política" (grifo nosso). Discordando das freqüentes comparações com o período Vargas, Oliveira ressalta que ao contrário da legislação trabalhista que criava direitos novos para o conjunto dos trabalhadores, o Bolsa Família se apresenta "como 'benesse' sujeita às contingências do orçamento. Além disso, "todas as medidas do governo são contra a centralidade do trabalho na política" (apud CARIELLO, 2006).

$\mathrm{Na}$ ausência de lutas coletivas organizadas, de instituições efetivamente representativas dos trabalhadores, prevalecem as políticas ditadas pelos representantes do capital - cada vez mais fortalecidos, senhores quase absolutos dos destinos da humanidade.

A bem da verdade, porém, não se pode imputar essa situação somente à ação governamental. O enfraquecimento das lutas e organizações dos trabalhadores, se por um lado é o efeito da fragmentação resultante das transformações nas condições objetivas do mundo do trabalho e das políticas de reforço à dependência e dispersão, por outro lado, ele também é realimentado dialeticamente pela concepção de política atualmente predominante na esquerda. Principalmente desde o fim dos anos 1980, quando a priorização - para não dizer exclusividade - da luta pela ocupação dos espaços de poder institucional teve como contrapartida o abandono da organização da classe a partir dos locais de trabalho e moradia.

O desafio da reconstrução de uma identidade de classe, unificando os diversos segmentos que dependem da venda de sua força de trabalho, requer a formulação de um projeto comum que terá que ser construído conjuntamente por todos esses segmentos, incluindo a grande massa dos chamados subproletários. Para Fiori (2006), os cerca de um bilhão de pessoas atualmente sem trabalho no mundo, ao contrário das teorias sobre o fim do trabalho, "seguem ligados ao mesmo paradigma do trabalho". O problema é que a "inevitável dispersão dos interesses, e da linguagem dos trabalhadores", resultante das transformações atuais, "vem dificultando a soldagem política dos seus diversos segmentos".

A fragmentação que atinge o conjunto da força de trabalho adquire dimensões infinitamente maiores no universo dos trabalhadores precarizados e desempregados onde a evidente instabilidade, a disputa pelas parcas oportunidades de ganho oferecidas pelo mercado, assim como pelas migalhas compensatórias oferecidas pelo Estado, vão na contramão de qualquer estímulo à organização coletiva. No entanto, mesmo considerando todas essas adversidades, apesar do menor peso político decorrente de sua posição secundária na cadeia produtiva e apesar de marginalizado inclusive pelas organizações sindicais, esse segmento pode ter um papel relevante de denúncia e confronto, pois "sua condição de despossuído e excluído o coloca potencialmente como um sujeito social capaz de assumir ações mais ousadas, uma vez que estes segmentos sociais não têm mais nada a perder no universo da sociabilidade do capital" (ANTUNES, 1995, p. 90). O que pode ser confirmado pela participação massiva nas inúmeras ocupações realizadas por movimentos de sem-teto e sem-terra, tanto na área urbana como rural.

\section{Considerações finais}

O aumento incessante desse verdadeiro 'exército de pedintes' aponta para a urgente necessidade de repensar o modelo de sociedade e a política econômica e social aplicada nos últimos anos, assim como exige um repensar da ação política por parte das forças empenhadas em fortalecer as organizações dos trabalhadores.

A carência até das necessidades mais elementares exige providências urgentes, que não podem esperar, sob o risco de acarretar a morte ou seqüelas muitas vezes irreversíveis na saúde física e mental. Por isso as ações emergenciais imediatas têm sentido e não podem ser simplesmente dispensadas.

O grande desafio é combinar essas ações de urgência com ações de longo prazo tendo em vista atacar as verdadeiras causas geradoras da pobreza e desigualdade. Desafio tanto mais difícil nos dias atuais, em que a predominância de ações fragmentadas tende a impedir a visão de totalidade. Ao contrário das lutas dos anos 1970 e 1980, a transformação social está hoje fora do horizonte. A militância política daquele período, voltada para a luta pela mudança estrutural da sociedade por meio da ação direta das classes trabalhadoras, foi substituída pelo 'voluntariado' cujo enfoque principal está na 'ajuda' individual, muitas vezes cumprindo a função inconsciente de apaziguar a consciência.

As políticas pontuais, fragmentadas e desconexas, em geral se destinam a compensar parte dos efeitos 'naturais' de um sistema inquestionável. Ações ou projetos quase sempre situados no terreno periférico das conseqüências, enquanto o capital continua no comando da esfera produtiva e dos principais núcleos de poder sem qualquer contestação.

Recorrendo novamente a Antunes (1995, p. 90), é importante ter claro que, apesar de sua "hete- 
rogeneização, complexificação e fragmentação", a "superação do capital somente poderá resultar de uma empreitada que aglutine e articule o conjunto dos segmentos que compreendem a classe que vive do trabalho".

\section{Referências}

ANTUNES, R. Adeus ao trabalho? São Paulo, Campinas: Cortez/Unicamp, 1995.

APOIO; BROT FÜR DIE WELT. Diagnóstico da fome na cidade de São Paulo. Projeto coordenado por Manoel Del Rio; Giuseppina de Grazia; Telma Nery. São Paulo, maio 2005. Mimeografado.

CAMPOS, A. et al. (Org.). Atlas da exclusão social no Brasil. V. 2. São Paulo: Cortez, 2003.

CARIELLO, R. Retórica getulista de Lula divide analistas. Folha de São Paulo, 2 jul. 2006, Caderno A, p.14.

CEBRAP-Centro Brasileiro de Análise e Planejamento. Áreas de Pesquisa. Disponível em <www.cebrap.org.br $>$. Acesso em: out. 2006.

CONSTANTINO, L. Trabalho bate Bolsa-Família na redução da desigualdade. Folha de São Paulo, 5 mar. 2006, Caderno A, p. 4.

FGV - Fundação Getúlio Vargas. Centro de Políticas Sociais. Pesquisas Recentes. Evolução recente da miséria. Disponível em <www.fgv.br/ibre/cps/Evolucao_Recente_ Miseria.cfm>. Acesso em: out. 2006.

FIORI, J. L.. Adeus à classe trabalhadora? Disponível em $<$ http://dhnet.org.br/w3/fsmrn/biblioteca/69_jose_luis fiori2.html>. Acesso em: 30 mar. 2006.

GÓIS, A. Arquivos da Folha, de 25.12.2005 2005. Pobres se distanciam de ricos e dependem mais do governo. Disponível em <www1.uol.com.br/cgi-bin/bibliot/arquivo .cgi?html=fsp2004>. Acesso em: out. 2006.

IAMAMOTO, M. O Serviço Social na contemporaneidade: trabalho e formação profissional. São Paulo: Cortez, 1998.

IBGE - Instituto Brasileiro de Geografia e Estatística. SIDRA - Sistema IBGE de Recuperação Automática. Disponível em:<http://www.sidra.ibge.gov.br/bda/default. asp? $\mathrm{z}=\mathrm{t} \& \mathrm{o}=1 \& \mathrm{i}=\mathrm{P}>$. Acesso em: out. 2006.

LAVINAS. L. O nó é outro. O Globo Online, Arquivo Premium, 4 abr. 2006. Disponível em $<$ http://arquivoglobo. globo.com/ie_index.htm>. Acesso em: out. 2006.
MÍNIMO é pouco eficiente no combate à pobreza, diz Ipea. Folha de São Paulo, São Paulo, 7 set. 2006, Caderno B, p. 3.

MONTAÑO, C. E. O projeto neoliberal de resposta à 'questão social' e a funcionalidade do 'terceiro Setor'. Revista Lutas Sociais, NEILS/PUC-SP, São Paulo: Ed. Pulsar, n. 8, p. 53-64, 1. sem. 2002.

NETTO, J. P. Crise do socialismo e ofensiva neoliberal. São Paulo: Cortez, 2001.

POCHMANN, M. Relação entre crescimento da economia e a desigualdade social gera divergência. Folha de São Paulo, 23 set. 2006a, Caderno B, p. 12.

. Juro faz dívida interna crescer R\$ 141 bi. Folha de São Paulo, São Paulo, 24 jan. 2006b, Caderno A, p. 1.

PNAD-Pesquisa Nacional por Amostra de Domicílio 2004. Disponível em <www.ibge.gov.br/home/estatistica/ populacao/trabalhoerendimento/pnad2004>. Acesso em: out. 2006.

RENDA financeira do rico sobre 66\%; a do trabalhador, 19\%. Folha de São Paulo, São Paulo, 9 jul., 2006, Caderno A, p. 6.

\section{Notas}

1 Apesquisa foi realizada pela APOIO(Associação deAuxílio Mútuo - entidade vinculada ao Movimento de Sem-Tetos do Centro-MSTC) e BrotFür Die Welt (Pão Para o Mundo - uma entidade da Igreja LuteranaAlemã, tradicional apoiadora de ONGs). Foram entrevistadas 46 famílias residentes tanto nas regiões centrais como na periferia do município de São Paulo, a partir da indicação de lideranças populares vinculadas a movimentos de sem-teto eà Pastoral da Criança. Trata-se de uma amostra aleatória, que buscou atingir situações diversificadas tanto em relação à composição familiar, condições de moradia (moradores de favelas, ocupações irregulares, cortiços, moradores de rua), como em relação às situações de trabalho e renda (desempregados, trabalhadores precarizados, assalariados). Embora não representativa do ponto de vista quantitativo, são utilizados aqui alguns dos depoimentos colhidos no desenvolvimento da pesquisa, por espelharem situações encontradas em abundância tanto em São Paulo como nas demais regiões metropolitanas das grandes cidades do país, além de refletir a trajetória socioeconômica característica das duas últimas décadas. As entrevistas foram realizadas após expresso consentimento dos participantes, de acordo com os procedimentos definidos na Declaração de Helsinque V, 1996, e na Resolução 196/96 do Conselho Nacional de Saúde (APOIO;BROTFÜRDIEWELT,2005). 
2 São Paulo, Rio de Janeiro, Porto Alegre, Recife, Salvador, Belém, Fortaleza, Curitiba, Belo Horizonte.

3 Oficialmente, só é incluído no chamado 'desemprego aberto' quem efetivamente procurou emprego nos 30 dias anteriores à entrevista. Do contrário, não é considerado desempregado, assim como quem declara ter exercido uma atividade remunerada qualquer, mesmo que apenas por uma hora na semana anterior à pesquisa.

4 Só a título de exemplo: no primeiro semestre de 2005, o lucro de 220 empresas cresceu $71 \%$ em relação ao primeiro semestre de 2003. No mesmo período, o lucro dos grandes bancos cresceu 49,3\%(FOLHADE SÃOPAULO, 2005). Também em 2005 a remessa de lucros e dividendos para o exterior por parte de multinacionais aqui instaladas cresceu $72,9 \% \mathrm{em}$ relação ao ano anterior, conforme dados do Banco Central.

5 Apenas para citar alguns dos muitos dados disponíveis: a porcentagem de pessoas responsáveis pelos domicílios sem nenhum rendimento dobrou nos anos 90 , passando de 4,87 em 1991 para 10,43\% em 2000 (IBGE, 2006). Nesse mesmo período, só no município de São Paulo, o número de pessoas vivendo abaixo da linha da pobreza subiu de 772 mil para 1,3 milhão(FGV,2006). Em2005, apesar de um pequeno recuo, o Centro de Políticas Sociais da Fundação Getúlio Vargas(FGV, 2006) ainda contabilizava 43 milhões de pobres no país (vivendo com menos de 121 reais per capita).

6 Estudo do Centro Brasileiro de Análise e Planejamento (CEBRAP) indica que o rendimento médio dos trabalhadores que se encontram entre os $10 \%$ mais pobres, caiu $39,6 \%$ entre 1995 e2004(CEBRAP,2006).

7 Em 2005, a carga tributária atingiu 36,5\% do PIB, enquanto os juros pagos, apropriados pelos bancos e demais detentores de títulos e aplicações financeiras foram equivalentes a $32 \%$ do PIB. (RENDA..., 2006).

8 Desconsiderando o fato de que são essas mesmas políticas (as quais exigem que você se distinga dos demais 'pedintes' apresentando-se como 'o mais miserável, o mais necessitado', etc.) que reforçam esse tipo de comportamento.

9 Cerca de um terço das pessoas (32,6\%) manifestou como primeiranecessidade: “terum lugarmelhor para morar"; $28, \%$ : "ter um emprego", e $26 \%$ referiram-se aos dois itens ao mesmo tempo: casa e emprego. Ainda, para 6,5\% "dar uma vida melhor para os filhos" ou "garantir o estudo dos filhos" $(4,3 \%)$ são vistos como o "maior sonho da vida".

\section{Giuseppina Rosaria de Grazia}

Doutora em Sociologia pela Universidade de São Paulo (USP)

Professora na Faculdade de Serviço Social

Universidade de Santo Amaro (UNISA)

Rua Isabel Schmidt, 349 - Santo Amaro
São Paulo - São Paulo

CEP: 04743-000 